\title{
THE SPHYGMOCHRON FOR CHRONOBIOLOGIC BLOOD PRESSURE AND HEART RATE ASSESSMENT IN CANCER PATIENTS
}

\author{
JULIA HALBERG, GERMAINE CORNÉLISSEN, FRANZ HALBERG, FRANCINE \\ HALBERG AND ERNA HALBERG
}

\section{INTRODUCTION}

Chronobiometry $(11,15)$, a subdiscipline of chronobiology*, serves, among other uses, for cardiovascular assessment of a cancer patient. This approach is advocated for everyone, in order to obtain individualized reference standards in health. The assessment of a reliable chronobiologic mean (the midline-estimating statistic of rhythm, briefly the MESOR) is particularly pertinent in the case of heart rate for patients with cancer who are treated with doxorubicin, where it can serve as a gauge of cardiotoxicity. The purpose of this chapter is to introduce the chronobiologic approach to the measurement of blood pressure and heart rate and to distinguish it from any conventional 24-hour ambulatory monitoring. The 24-hour profile (carried out without chronobiologic analyses) is a valuable yet incomplete substitute for the conventional casual spotchecks, currently practiced for convenience rather than at pertinent times.

\section{CASUAL MEASUREMENTS}

In measuring blood pressure, a conventional approach seeks to identify values that are too high or too low with respect to time-unspecified reference standards $(35,39)$. This conventional inquiry based on casual spotchecks can be questioned as wasteful (18). Indeed, the outcome of large-scale clinical trials such as the Australian Therapeutic Trial in Mild Hypertension (see 18 for discussion) reflects the status quo. Out of nearly 2,000 individuals in this study who received a placebo, $48 \%$ responded to this 'treatment', most of them within less than a year. This fact renders that 'office-hypertension' or 'white-coat hypertension' associated with the excitement of visits to a physician's office leads to the entry into large-scale studies of many false positive cases $(5,18,38,39)$. Taking 'the' blood pressure at health fairs or in shopping centers is a put-on (18). The physician can consult at least the personal and familial history of high blood pressure and/or related disease.

The placebo effect in studies such as the Australian trial (18) may be contributed in part by a substantial error in diagnosis, not only at the outset of a study (false positives entering the study), but also by false negative diagnoses contributing to the outcome at the completion of a study.

\footnotetext{
* Chronobiology is the study (logos) of time (chronos) in the fabric of life (bios), characterized by rhythms, defined as algorithmically validated, reproducibly recurring dynamics (11).
}

The outcome is somewhat less ambiguous in those studies relying on endpoints such as morbidity and mortality; yet in these cases as well, the uncertainty associated with the diagnosis at the entry into the study may greatly complicate or even invalidate the outcome (18). Whether individuals who respond to stimuli such as a physical examination by blood pressure elevation are at an increased risk remains a matter for further chronobiologic research. Such individuals may already reveal an alteration of dynamic rhythm characteristics as a harbinger of subsequent MESOR-hypertension (17, 127).

\section{Ambulatory blood pressure monitoring, ABPM}

Indications for ambulatory blood pressure monitoring have been restricted to special groups of patients, notably those with 'borderline hypertension' for whom office and home measurement disagree markedly. Certain basic questions have been raised before recommending ABPM for routine diagnostic use in the clinical setting. Among these questions, Weber, notwithstanding earlier chronobiologic contributions $(3,39)$, points to the difficulty of interpreting the data ABPM generates (38). The computation of mean values and the inspection of a single 24-hour record, which can hardly predict a given pattern's uncertainty on subsequent days, indeed may be improved by computing the percentage of measurements above some arbitrary limit as an assessment of load (38). Critical limits should, however, be adjusted to account for the predictable variability in blood pressure. Moreover, visual inspection alone cannot resolve sensitive parameters that may be informative in their own right. Restriction of monitoring to 24 hours and to special categories of individuals, a useful first step, may lead a priori to an as-yet indeterminate number of false negative and false positive diagnoses and should be replaced by more general and extensive chronobiologic approaches discussed below. Since chronobiologic methodology will also focus on a rhythm alteration more broadly, cost-effectiveness may thereby be improved, rather than violated. The objective clarification of this point is an urgent matter of research.

\section{Chronobiology}

Chronobiologists advocate, for everyone, cancer patients included, both automatic monitoring and the interpretation of (even single time-specified and) serial measurements in 
the light of time-varying reference standards. Monitoring for at least 48 hours, if possible, is advocated since two 24-hour profiles can have means which differ substantially $(4,18)$. Special chronobiologic methods serve for analyses beyond the computation of conventional means (over 24 hours and separately for the day and the night spans), standard deviations and coefficients of variation, the inspection of data for the determination of the peak and the nadir, and a comparison of all values with time-unspecified limits such as $140 / 90 \mathrm{~mm} \mathrm{Hg}$. Chronobiologic analyses yield new endpoints that allow predictions with estimates of the uncertainties involved $(3,4,5,7,11,15,17,18,25,27,36)$.

\section{Parametric and non-parametric endpoints}

Some of the new endpoints are inferential statistical parameters: an improved 24-h mean, the MESOR; the amplitude (half the total predictable difference between high and low values); the acrophase (an indication of the times when high values are more likely to occur overall); and the period. Confidence intervals provide some measure of uncertainty, while $90 \%$ prediction limits (chronodesms) serve as reference limits for dynamic characteristics of change. The MESOR is superior to the arithmetic mean as a location index when measurements are unequally spaced. For equally-spaced measurements, the MESOR is identical to the mean, yet when the data are characterized by a rhythm, the MESOR has a smaller uncertainty than that of the arithmetic mean. For the individual patient, the effect of a treatment may be rigorously validated by a MESOR test, when a comparison of means by a t-test fails to achieve this task. Nonparametric features of numerical integration over time include time-tension products reflecting the extent of any excess (or deficit), the time when excess (or deficit) is most likely to occur and the duration of elevation (or deficit) within a 24-h day. These endpoints are obtained by a comparison of the patient's profile with reference chronodesms also serving for the interpretation of single time-specified measurements (18).

\section{The sphygmochron}

There are charts called the long and short form of the 'sphygmochron' (sfig' - mo kron). Sphygm denotes a relation to the circulation - a sphygmomanometer is the device used to measure blood pressure - and chron (from chronos) refers to a rigorous evaluation over time. The sphygmochron is a computer-prepared comparison of a given individual's data with those of clinically healthy individuals of the same age and gender (peers), if not with earlier data of the same subject. The reference data base is summarized as time-specified ranges or regions for single values or rhythm parameters, which can involve more components (harmonics) than the 24- and 12-h cosine curves, the most prominent features in the circadian waveform of most individuals.

A computer helps to fill out the sphygmochron, using the blood pressure and heart rate measurements collected over at least two full days, and for longer spans if necessary. The computer calculates the circadian rhythm parameters and any measure of excess or deficit. These characteristics indicate, for the individual patient, whether values or the characteristics computed from them are within the timevarying peer group limits or outside these chronodesms. Values outside the chronodesms are of interest as an estimate of the amount of time and the extent to which an individual's blood pressure or heart rate will be deviant, perhaps as a function of chemotherapy, increasing the risk of health problems. The 24-hour time-tension product assessing excess should be less than $50 \mathrm{~mm} \mathrm{Hg} \times \mathrm{h}$ over 24 hours. If this is not the case, interventions should be recommended in order to achieve this goal.

The sphygmochron can help the physician prescribe timing as well as dosing. Medication can be taken in such a way as to lower blood pressure or heart rate at the times when the individual would have high values, if left untreated. This timing of treatment not only makes the medication more effective, it also avoids reducing the blood pressure at times when it is already low, leading to the dizziness many people experience when taking medication for high blood pressure. A follow-up sphygmochron can be completed while one takes medication, often allowing the physician to prescribe the timing of drugs in order to reduce or reschedule dosages and help prevent undesirable or harmful side-effects. Timing antihypertensive treatment is particularly indicated in the case of amplitude-hypertension $(18,27)$ or when insufficient conventional treatment by drugs reduces the MESOR but enlarges the amplitude, the extent of predictable variation (18).

\section{A sphygmochron should be used routinely}

Cancer patients, among others, might appear to be welltreated for high blood pressure, yet have (undetected) undesirably high pressures or fast heart rates at odd times. Alternatively, one may be overtreated by antihypertensive medication when actually much less medication is needed, if given at the right time.

To summarize, features of the chronobiologic approach include: 1. monitoring all rather than a select group of individuals to obtain individualized reference standards; 2. starting monitoring early in life, preferably at birth $(17,18)$; 3. monitoring over at least a 48-h span; 4. interpreting the record by reference to chronobiologic standards relying on living healthy peers.

The following clinical case serves for the purpose of illustrating the application of chronobiologic methodology, including a demonstration of tests of statistical significance applicable to the given patient, as a step toward rendering the art of treatment into a science. With the availability of ambulatory monitors, the test for statistical significance of a change in blood pressure or heart rate should always be considered, in addition to the also-indispensable consideration of clinical significance.

\section{CLINICAL CASE}

A 39-year-old woman, diagnosed $\sim 1.5$ years earlier to have elevated blood pressure, was treated daily (in the morning) for this condition with $12.5 \mathrm{mg}$ of spironolactone and 
Table 1. Cardiovascular profiles of a 39-year-old woman treated for metastatic breast cancer and high blood pressure*

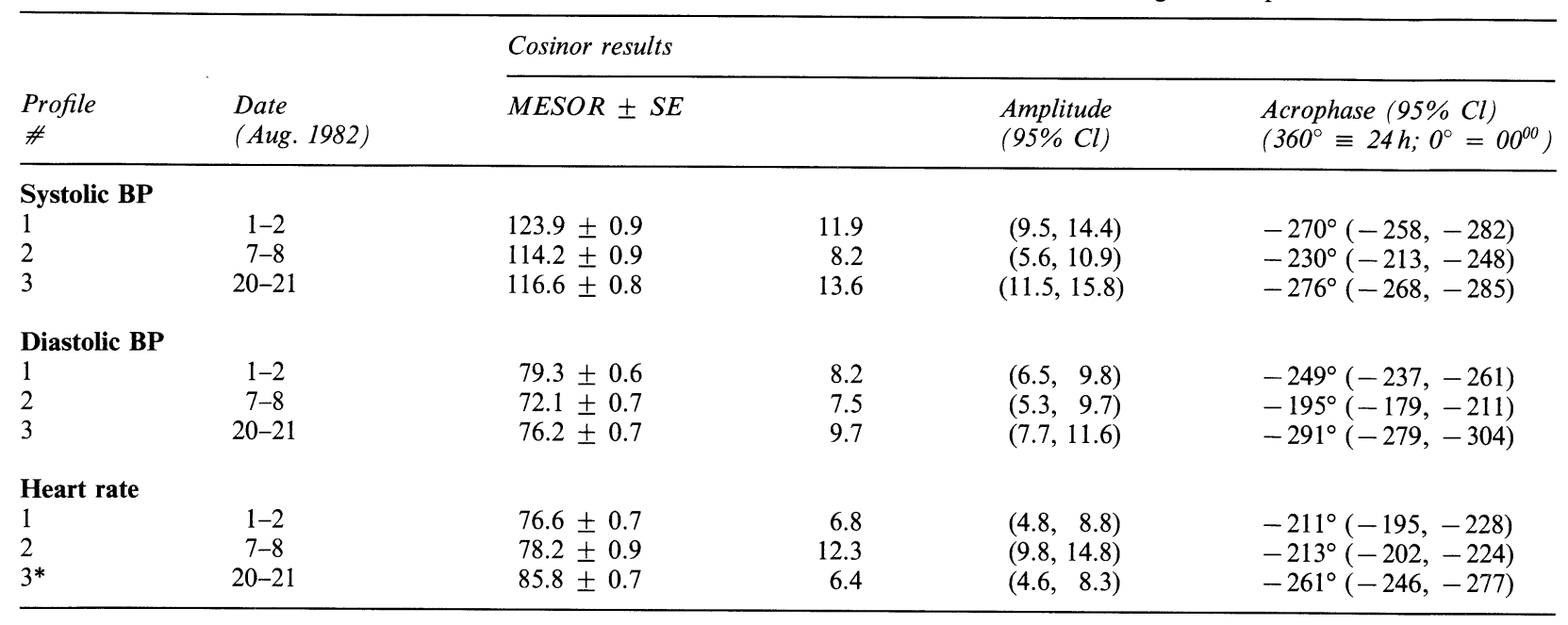

* Blood pressure (BP) in $\mathrm{mm} \mathrm{Hg}$; heart rate in beats/min. $\mathrm{N}$ of measurements are 102,85 and 85 for profiles 1,2 and 3 , respectively. State 5 months after removal of the left breast and adjuvant chemotherapy, including a total of $300 \mathrm{mg}$ of doxorubicin. Three around-the-clock profiles are summarized above, one 15 and another 22 days after the last oncologic combination treatment, Rxo (with 50 mg [cardiotoxic] doxorubicin, $500 \mathrm{mg}$ cytoxan and $1.5 \mathrm{mg}$ vincristine) and a third profile 3 days after another course of the same Rxo. The patient received concomitant daily treatment with $12.5 \mathrm{mg}$ of spironolactone and $12.5 \mathrm{mg}$ of hydrochlorothiazide, continued unchanged throughout span investigated. P from zero-amplitude test for rhythm detection <.001 in each (not shown). For inter-profile changes see Table 2.

$12.5 \mathrm{mg}$ hydrochlorothiazide (one-half tablet of $25 \mathrm{mg}$ / $25 \mathrm{mg}$ of Aldactazide). In March 1982, she underwent a left mastectomy for a biopsy-proven infiltrating ductal carcinoma. At the time of surgery, 5 of 16 lymph nodes contained metastatic tumor, with the same histology as the breast neoplasm. In August 1, 1987, after having received a cumulative dose of $300 \mathrm{mg}$ doxorubicin, the patient's blood pressure and heart rate were monitored at 10-minute intervals with a room-restricted instrument, manufactured by Nippon Colin Ltd. (Komaki, Japan), connected to a personal computer in the patient's home. Around-the-clock profiles obtained on several occasions were analyzed by chronobiologic methods.

Table 1 shows the circadian characteristics of blood pressure and heart rate for 3 consecutive profiles. A rhythm is demonstrated in each case. The model accounts for from 30 to over $50 \%$ of the total variation. Tests of changes in the circadian characteristics, shown in Table 2, reveal a decrease in blood pressure MESOR between the first and third profiles. This decrease is statistically significant but is not necessarily relevant to a dose modification, since infradian variations can bring about statistically significant changes as well. This comment also applies to a statistically significant increase in the circadian amplitude of heart rate between the first and the second profile, followed by an increase in heart rate MESOR, Figure 1. The statistical significance of a change, while it is a sine qua non for rigorous inferences, is not in itself a sufficient condition for biologic significance. The latter must be judged in a broader context of earlier data.

Since an increased circadian amplitude of blood pressure can be a harbinger of a MESOR increase (27), the question may be raised whether similar changes in heart rate may have been associated with the known cardiotoxicity of doxorubicin (5). The increase in the circadian amplitude of heart rate occurs, however, with a relatively long lag after the last doxorubicin treatment on July 17 , and hence could be an infradian change. By contrast, the MESOR increase in the profile on August 20 occurs rather soon after doxorubicin treatment on August 17. This increase is statistically significant, as shown in Table 2 and could well be a harbinger of cardiotoxicity. Accordingly, the doxorubicin-containing treatment was replaced by methotrexate and 5-fluorouracil. By the time of the change in therapy, however, the damage to the patient's heart was apparently irreversible. A switch to other, presumably non-cardiotoxic therapy notwithstanding, the patient died $\sim 5$ months later of congestive heart failure.

This clinical case demonstrates the feasibility, by 1982, of chronobiologic cardiovascular home monitoring prompting modifications of the treatment. It is recommended that the cardiovascular monitoring of cancer (and other) patients receiving potentially cardiotoxic treatment be implemented by ambulatory monitoring at the outside and followed longitudinally (rather than only by 48-hour profiles, as in Fig. 1) for the early detection of cardiotoxicity (5) and a timely change in medication, if need be. Such longitudinal monitoring is the more important since it can assess the extent of spontaneous change in a given subject. In the clinical case discussed herein, if we restrict our attention to the three profiles compared in Tables $1-2$, one is certainly led to believe that the MESOR increase was a result of cardiotoxicity (5). Figure 1, however, shows a broader picture. It reveals a lower heart rate MESOR after discontinuance of the doxorubicin-containing treatment, on September 9, as anticipated. On September 11 and again on September 25, however, following a different, presumably non-cardiotoxic treatment, a large heart rate MESOR is again seen. In this case, it cannot be decided whether, on September 25 and October 4, one is dealing with an expression of congestive 


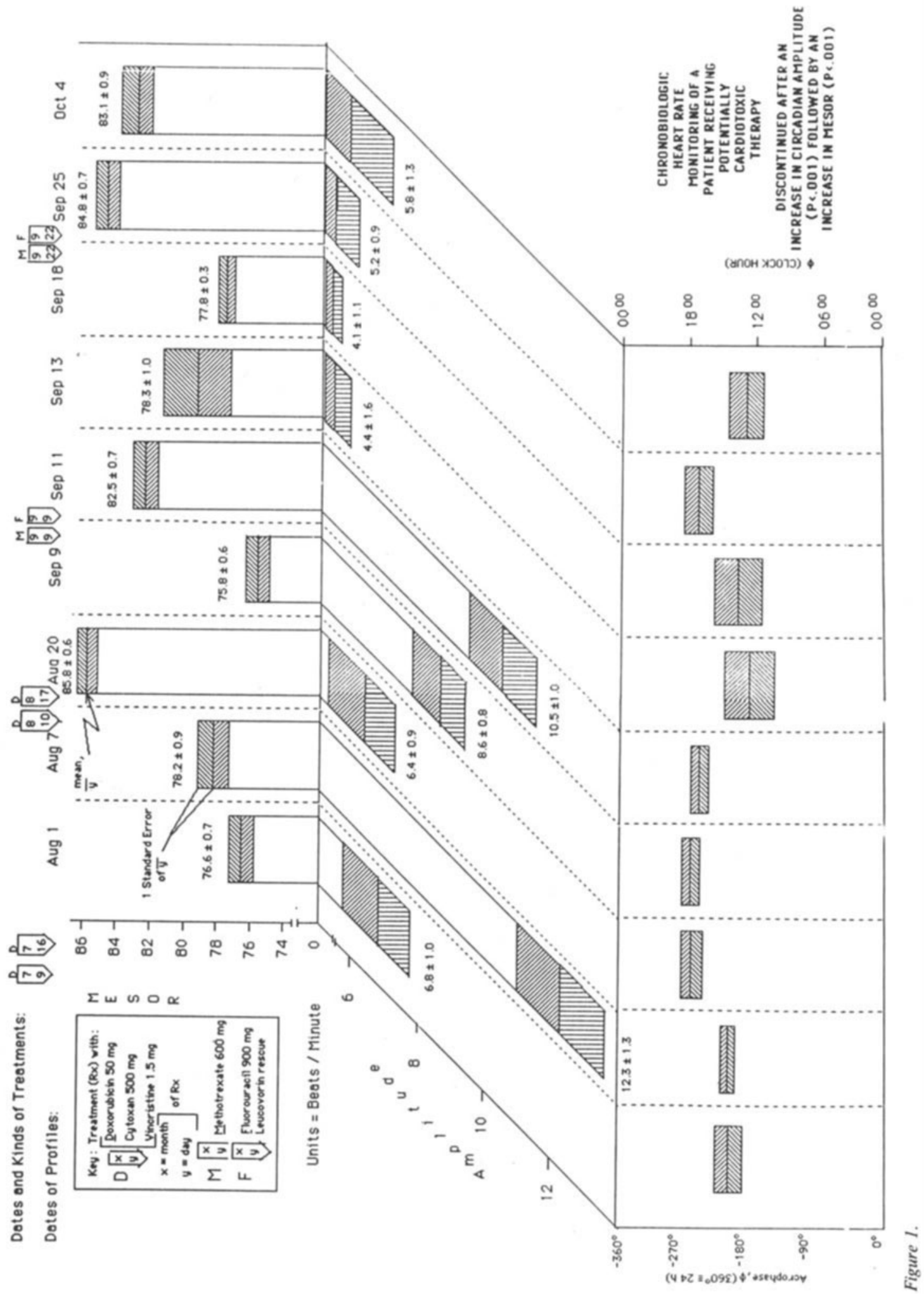


heart failure or with a spontaneous variation. Had one had serial MESORs in longitudinal studies with around-theclock monitoring, each day from the start of treatment, one could have tested statistically whether a given change in a rhythm characteristic (MESOR, amplitude or acrophase) was within or outside the limits of individualized standards of infradian variation. In such prospective studies, the changes in MESOR may be much more reliably interpreted on an individualized basis. Miniaturized instrumentation for such purposes is within the state of the art, even if it is not commercially available. Such instrumentation will be required if death from the cardiotoxic chemotherapy is to be prevented by timely action. Results such as those in Table 1 and 2 should be routinely given on the back of follow-up sphygmochrons, to assess the time course of a condition, as in this case, and in particular the success or failure of a given treatment.

\section{TASKS AHEAD}

Very often in medicine and more so in facing a patient with coexisting disease conditions, such as the infiltrating ductal carcinoma and high blood pressure in the clinical case discussed above, a variety of medical issues have to be addressed. In this particular case, the cardiotoxicity of the previously prescribed doxorubicin, apart from the fait accompli of prior treatment for an elevated blood pressure, was the clinical problem that needed attention as much as the cancer treatment itself. Under the circumstances, little could be done. A diagnostic reevaluation of the "hypertension' or of finer points such as a question of free-running vs. synchronization of the circadian cardiovascular rhythms $(11,20)$ was beyond the scope of a consultation, nor was there any opportunity to consider chronotherapy for high blood pressure $(6,40)$ or of cancer $(21)$.

A broader perspective of the tasks on hand is the more important. One should consider what could have been done by treatment initiated earlier and chronobiologically. One may ask what research must focus on in order to eventually prevent both disease conditions. For prevention as well as treatment, rhythms with several frequencies have been found to be relevant in the clinical case in this chapter, as in the other contributions on approaches by chronobiology to cancer in this book $(5,9,29,30)$. Today, circadian rhythms start to be emphasized and exploited. But optimization according to infradian rhythms should also become practical in medicine.

From a chronoepidemiologic viewpoint, the circannual amplitude of prolactin and TSH have been related to the risk of developing breast cancer $(19,37)$ and the circannual amplitude of aldosterone to cardiovascular disease risk (19). These results stem from international studies of clinically healthy women of 3 age groups studied around-the-clock in each season. The circannual amplitude of plasma prolactin is low and that of plasma TSH is high in women at high risk of developing breast cancer (19). In adult women with fibrocystic disease of the breast, also characterized by an increased risk of developing breast cancer, there is also a damping of the circannual amplitude of plasma prolactin (37).

A model of the murine carcinogenesis, related to the prolactin secreted abundantly by an ectopic pituitary, initiated by the gland removed from its proximal neurohumoral coordination in the sella turcica, is interesting, since it implies that local neuroendocrine interactions are critical. Ectopic pituitary-induced carcinogenesis in the mouse breast can be reversed by no more than the addition of a hypothalamus to the ectopic pituitary $(16,21)$. The 'replace' approach is thus selective, since the entire brain is not required for the reversal. Hormonal cycles may be involved in these processes of early carcinogenesis and neurohumoral factors may interact in a partial or complete reversal.

From a clinical viewpoint, a given treatment may be more or less effective, depending on the circannual stage. This has been shown to be the case for oncostatic agents such as doxorubicin and cisplatin (13) as well as for cyclosporine, a drug acting upon immunity, a function also pertinent to a patient's response to cancer therapy. Lentinan, a potential immunomodulator, can modify, in either direction, the host's response to a subsequent cancerous growth (8). Depending on the circadian-circaseptan pattern of its administration, lentinan enhances or delays the growth of a subsequently implanted myeloma; and this effect depends further on the stage of circannual rhythms at treatment time. In the context of multifrequency interactions, it is interesting that some aspects of the circadian cell cycle also undergo circannual changes $(31,34)$. Recent results from studies on immunology and shifts of the circadian synchronizer have shown that apart from optimizing the circadian stage of treatment, benefits could be derived from repeatedly changing treatment times. Such a strategy may benefit the host by spread-
Figure 1. Clinical case. Changes in rhythm characteristics of heart rate of a patient receiving cardiotoxic treatment for metastatic breast cancer. Interpretation is difficult, notwithstanding the statistical significance of the changes occurring among the first 3 profiles shown in Table 2. The contribution of infradian rhythms cannot be ruled out. Admittedly with a posteriori reasoning, one may be tempted to see an increase in the circadian amplitude preceding the increase in MESOR on August 20, that could be discussed as a possible harbinger of cardiotoxicity by virtue of its occurrence promptly after the administration of cardiotoxic treatment. Results of follow-up heart rate monitoring of the patient in six additional profiles suggest that caution is warranted. It can be seen that changes occur not only before but also after discontinuation of the cardiotoxic treatment. A lasting cumulative role of the prior cardiotoxic treatment cannot be ruled out. The patient's conditioned response to a treatment that previously constituted a cardiotoxic and other burden also comes to mind.

For statements that are valid on an individualized basis, it is important to assess spontaneous fluctuations. In this clinical case, monitoring was started so late that the changes shown in this figure cannot be separated from a trend toward congestive heart failure, which eventually killed the patient. If the spontaneous rhythmic changes could have been monitored for several months earlier, starting at least at the onset of treatment, their extent could have provided an individualized reference standard to assess treatment effects. If so, ambulatory monitoring with chronobiologic assessment, as here advocated, could have overcome a traditional dilemma in clinical treatment. Long-term monitoring (perhaps with miniaturized devices inplanted at the time of diagnosis, once these will be developed) remains the long-term goal of a chronbiologic approach to the cancer patient. 
Table 2. Test of equality of rhythm characteristics in 3 blood pressure and heart rate profiles of a 39-year-old woman treated for metastatic breast cancer and high blood pressure*

\begin{tabular}{|c|c|c|c|}
\hline \multirow[b]{2}{*}{ Parameter $(s)$} & \multicolumn{3}{|c|}{ Systolic blood pressure } \\
\hline & $d f$ & $F$ & $P$ \\
\hline \multicolumn{4}{|c|}{ August $1-2 / 20-21,1982$} \\
\hline MESOR, M & $(1,180)$ & 39.05 & $<0.001$ \\
\hline amplitude, A & $(1,181)$ & 1.07 & 0.302 \\
\hline acrophase, $\phi$ & $(1,175)$ & 0.74 & 0.392 \\
\hline$(\mathrm{A}, \phi)$ & $(2,181)$ & 1.16 & 0.315 \\
\hline$(\mathrm{M}, \mathrm{A}, \phi)$ & $(3,181)$ & 12.88 & $<0.001$ \\
\hline \multicolumn{4}{|c|}{ August $7-8 / 20-21,1982$} \\
\hline MESOR, M & $(1,157)$ & 3.90 & 0.050 \\
\hline amplitude, A & $(1,156)$ & 9.84 & 0.002 \\
\hline acrophase, $\phi$ & $(1,121)$ & 17.01 & 0.001 \\
\hline$(\mathrm{A}, \phi)$ & $(2,164)$ & 18.63 & $<0.001$ \\
\hline$(\mathrm{M}, \mathrm{A}, \phi)$ & $(3,164)$ & 14.96 & $<0.001$ \\
\hline & \multicolumn{3}{|c|}{ Diastolic blood pressure } \\
\hline \multicolumn{4}{|c|}{ August $1-2 / 20-21,1982$} \\
\hline MESOR, M & $(1,171)$ & 10.62 & 0.001 \\
\hline amplitude, A & $(1,170)$ & 1.30 & 0.256 \\
\hline acrophase, $\phi$ & $(1,179)$ & 20.09 & $<0.001$ \\
\hline$(\mathrm{A}, \phi)$ & $(2,181)$ & 12.89 & $<0.001$ \\
\hline$(\mathrm{M}, \mathrm{A}, \phi)$ & $3,181)$ & 11.58 & $<0.001$ \\
\hline \multicolumn{4}{|c|}{ August $7-8 / 20-21,1982$} \\
\hline MESOR, M & $(1,163)$ & 15.41 & 0.001 \\
\hline amplitude, A & $(1,162)$ & 2.04 & 0.155 \\
\hline$(\mathrm{A}, \phi)$ & $(2,164)$ & 39.84 & $<0.001$ \\
\hline$(\mathrm{M}, \mathrm{A}, \phi)$ & $(3,164)$ & 34.93 & $<0.001$ \\
\hline \multicolumn{4}{|c|}{ August 1-2/7-8, 1982} \\
\hline MESOR, M & $(1,169)$ & 2.25 & 0.135 \\
\hline amplitude, $\mathrm{A}$ & $(1,164)$ & 11.76 & 0.001 \\
\hline acrophase, $\phi$ & $(1,165)$ & 0.02 & 0.886 \\
\hline$(\mathrm{A}, \phi)$ & $2,181)$ & 6.16 & 0.003 \\
\hline$(\mathrm{M}, \mathrm{A}, \phi)$ & $(3,181)$ & 5.33 & 0.002 \\
\hline \multicolumn{4}{|c|}{ August $7-8 / 20-21,1982$} \\
\hline MESOR, M & $(1,152)$ & 49.73 & $<0.001$ \\
\hline amplitude, A & $(1,152)$ & 14.01 & $<0.001$ \\
\hline acrophase, $\phi$ & $(1,146)$ & 19.86 & $<0.001$ \\
\hline$(\mathrm{A}, \mathrm{Pf})$ & $(2,164)$ & 19.01 & $<0.001$ \\
\hline$(\mathrm{M}, \mathrm{A}, \phi)$ & $3,164)$ & 31.36 & $<0.001$ \\
\hline \multicolumn{4}{|c|}{ August $1-2 / 20-21,1982$} \\
\hline MESOR, M & $(1,181)$ & 91.68 & $<0.001$ \\
\hline amplitude, A & $(1,181)$ & 0.07 & 0.795 \\
\hline acrophase, $\phi$ & $(1,181)$ & 14.3 & $<0.001$ \\
\hline$(\mathrm{A}, \phi)$ & $(2,181)$ & 9.27 & 0.001 \\
\hline$(\mathrm{M}, \mathrm{A}, \phi)$ & $(3,181)$ & 40.37 & $<0.001$ \\
\hline
\end{tabular}

* See footnote to Table 1.

ing defense mechanisms allowing not only for 'killing the last cell' (2), but what may be even more important, for the first cell kill.

A basis for dramatic interindividual differences (in a population) in proneness to cancer may be found in the intra-individual spectrum of host rhythms already mapped at all levels of organization pertinent to carcinogenesis. The cell cycle $(31,34)$, the immune surveillance of the cell cycle $(2,26)$, and the neuroendocrine feedsidewards modulating defense (20), are pertinent. Rhythm stages are critical for all these functions. They also affect a patient's response to treatment, both from a therapeutic viewpoint $(9,12)$ and from the viewpoint of toxic side effects $(5,21,23)$. Rhythm stages have also been shown to be critical for carcinogenesis, for instance in the case of the circadian susceptibility to DMBA $(21,24)$. As noted earlier, rhythm stages have even been shown to be important to determine the risk of developing breast cancer and other diseases. The hours of changing resistance have been amply documented in different laboratories $(14,28,32,33)$. The response to wholebody irradiation, i.e., the dose that kills $50 \%$ of the animals in 30 days $\left(\mathrm{LD}_{30}^{50}\right)$, also changes drastically as a function of the host's circadian timing $(10,28)$, as does the nonlethal body weight loss associated with exposure to partial body irradiation. Chronorisk, as a concept, may well apply to carcinogenic, much lower doses of radiation, as it does to a host of other agents. This is the more likely since the circadian stage dramatically determines the outcome of chemical carcinogenesis (24). The concept of chronorisk is thus found to be critical at all stages, not only treatment but also induction and promotion, and even earlier.

This state of affairs leads us to ask whether early chronorisk assessment may not be utilized with an aim of prevention. To turn back to blood pressure, differences in the dynamics of blood pressure may already be detected at birth. A larger circadian and circaseptan amplitude characterizes babies with a positive as compared to those with a negative family history of high blood pressure. The two groups may differ even in their circannual modulations of the circadian blood pressure amplitude and MESOR (17, 18). Chronorisk may be formulated as a constellation of unfavorable acrophases in circadian rhythmic risk factors. Circannual rhythms modulate circadian rhythms not only in the newborn but even during pregnancy (18).

Chronobiology also aims at a timely prevention. The late John J. Bittner (discoverer of the first mammalian breast cancer agent, or virus) already emphasized, that genetic and acquired endocrine features were critical aspects of mammary carcinogenesis, interacting with the agent which bore his name (1). Intuitively, he anticipated the description of intermodulation among several frequencies characterizing rhythms that may coordinate certain natural killer cell subpopulations that patrol at the level of the cell cycle. Bittner made a major discovery by an astute observation of what happened when the progeny of mice of an inbred strain with a high breast cancer incidence were foster-nursed by animals of a strain with a low such incidence. The animals were mostly free of breast cancer. Just as Bittner's weaning experiments have been reproduced innumerable times, so a spectrum of rhythms is now amply documented $(14,32,33)$. The external biologic response modifiers can and should exploit the spontaneous rhythmic changes in host response $(2,22)$.

Chronorisk characterizes organisms throughout life, before a cancerous process is induced, at initiation and thereafter. Endeavors to reduce such risk may be started very early in life. In the ectopic pituitary in the mouse, chronorisk can be largely reversed. Future chronobiologists are challenged to achieve the same result in human beings. The five chapters on chronobiology are dedicated to the memory of John J. Bittner, who built the first chronobiology laboratory, at the University of Minnesota. 


\section{ACKNOWLEDGEMENT}

The clinical case presented in this chapter was originally summarized by us with Prof. David Kiang and Mr Robert Kelsey for the Proceedings of the 1st World Conference on Clinical Chronobiology, held in Monte Carlo, Monaco, March 17-20, 1988.

\section{SUPPORT}

U.S. Public Health Service (GM-13981 and HL-40650); Colin Medical Instruments (Komaki, Japan); Hoechst Italia Foundation (Milan, Italy); Medtronic Inc. (Minneapolis, MN, USA); Dr. h.c.Dr.h.c. Earl Bakken \& Dr. Betty Sullivan Funds.

\section{REFERENCES}

1. Bittner JJ: Texas Rep Biol Med 10: 160-166, 1952.

2. Carandente F, Dammacco F, Halberg F (eds.) Chronoimmunomodulation by an Antimicrobial Agent, 1989. Chronobiologia 15, \#1 \& 2, $194 \mathrm{pp}, 1988$.

3. Carandente F, Halberg F (eds.) Chronobiology of Blood Pressure in 1985. Chronobiologia 11, \#3, 152 pp., 1984.

4. Cornélissen G: In: Chronobiotechnology and Chronobiological Engineering, Scheving LE, Halberg F, Ehret CF, eds., Martinus Nijhoff, Dordrecht, The Netherlands, pp. 241-261. (See also pp. 262-269, 270-277, 278-281, 282-288, 289-298, 299-303, 304-309, and 310-317.) 1987

5. Cornélissen G, Halberg F: In: This series, HE Kaiser (ed.), Volume IX, AL Goldson (ed.), pp. 103-133, Dordrecht, Kluwer Academic Publishers, 1989.

6. Güllner HG et al:: The Lancet, p. 527, 1979.

7. Haen E, Halberg F: Deutsches Ärzteblatt 82: 3837-3948, 1985.

8. Halberg E, Halberg F: Chronobiologia 7: 95-120, 1980.

9. Halberg Francine, et al.: this volume.

10. Halberg F: Cold Spr Harb Symp quant Biol 25: 289-310, 1960.

11. Halberg F: Ann Rev Physiol 31: 675-725, 1969.

12. Halberg F: Guest Lecture, Proc 30th Ann Cong Rad, January 1977, Post-Graduate Institute of Medical Education and Research, Chandigarh, India.

13. Halberg F: In: Cellular Pacemakers, D.O. Carpentered, John Wiley \& sons Inc., New York, pp. 261-297, 1982.

14. Halberg F: Am J Anat 168: 543-594, 1983.

15. Halberg F, Bingham C: Proc. Biopharmaceutical Section, Am Statistical Assn, Chicago, Illinois, pp. 11-32, 1987.

16. Halberg F, et al.: Proc Soc exp Biol (N.Y.) 102: 650-654, 1959.
17. Halberg F, et al.: Postgrad Med 79: 44-46, 1986.

18. Halberg F, et al.: Chronobiology of humanblood pressure. Medtronic Continuing Medical Education Seminars, 4th ed., 242 pp., 1988.

19. Halberg F, et al.: In: Neoplasms - Comparative Pathology of Growth in Animals, Plants and Man, H Kaiser ed., Williams and Wilkins, Baltimore, pp. 553-596, 1981.

20. Halberg F, et al.: Circulation 34: 715-717, 1966.

21. Halberg F, et al.: In: Proc. XIV Int Cong Therapeutics, Montpellier, France, L'Expansion Scientifique Française, pp. 151196., 1977.

22. Halberg F, Halberg E: In: Pharmacokinetic Basis for Drug Treatment, LZ Benet, N Massoud, JG Gambertoglio eds., Raven Press, New York, pp. 221-248, 1984.

23. Halberg F, et al.: Experientia (Basel) 29: 909-934, 1973.

24. Halberg F, et al.: In: Biomathematics and Cell Kinetics, AJ Valleron and PDM Macdonald eds., Elservier/North-Holland Biomedical Press, Amsterdam, pp. 175-190, 1978.

25. Halberg F, Reale L, Tarquini B (eds.) Proc. II Int Symp on Chronobiologic approach to social medicine (Florence, Oct. 2, 1984). Istituto Italiano di Medicina Sociale, Rome, 1986. (See pp. 65-104, 345-366, 395-394, 417-426, 557-568, 569-574.)

26. Halberg F, et al:: In: Advances in Immunopharmacology, J Hadden L, Chedid P, Dukor F, Spreafico D, Willoughby eds., Pergamon Press, Oxford, pp. 463-478, 1983.

27. Halberg J, et al.: Int J Chronobiol. 7: 17-64, 1980.

28. Haus E, et al.: In: Space Biology, Tobias CA, Todd P eds., Academic Press, New York/London, 1974, pp. 435-474.

29. Hermida RC, Halberg F: this volume a.

30. Hermida RC, Halberg F: this volume b.

31. Lærum OD, et al:: Chronobiology int. 5: 19-35, 1988.

32. Pauly JE: Am J Anat. 168: 365-388, 1973.

33. Scheving LE: Endeavour 35: 66-72, 1976.

34. Sletvold O, et al.: Mechanisms of Ageing and Development 42: 91-104, 1988.

35. Strasser T: J Hypertension 4: 383-386, 1986.

36. Tarquini B (ed.) Social Diseases and Chronobiology: Proc. 3rd Int Symp Social Diseases and Chronobiology, Florence, Italy, Nov. 29, 1986, Societá Editrice Esculapio, Bologna. (See pp. 113-122, 123-128, 129-133, 135-144, 145-151, 209-220, 221-224, 225-233, 373-380 and 471-476.) 1987

37. Tarquini B, et al.: Am J Med. 66: 229-237, 1979.

38. Weber MA: Mayo Clin Proc. 63: 1151-1153, 1988.

39. Weber MA, et al.: In: Scheving LE, Halberg F, Ehret CF (eds.) Chronobiotechnology and Chronobiological Engineering. Martinus Nijhoff, The Netherlands, pp. 270-277, 1987.

40. Zaslavskaya R, et al.: Abstract III Int Symp 'Social Diseases and Chronobiology', Florence, November 29, Tarquini B, Vergassola R eds., p. 79, 1986. 